Case Report

\title{
Woman with Pregnancy and Lactation-Associated Osteoporosis (PLO)
}

\author{
Nasrin Bazgir $\mathbb{D}^{1},{ }^{1}$ Elham Shafiei $\mathbb{D},{ }^{2}$ Neda Hashemi $\mathbb{D}^{3},{ }^{3}$ and Hassan Nourmohamadi ${ }^{4}$ \\ ${ }^{1}$ Department of Rheumatology, Medical School, Ilam University of Medical Sciences, Ilam, Iran \\ ${ }^{2}$ Clinical Research Development Unit, Shahid Mostafa Khomeini Hospital, Ilam University of Medical Sciences, Ilam, Iran \\ ${ }^{3}$ Rasoul Akram Hospital, Iran University of Medical Sciences, Tehran, Iran \\ ${ }^{4}$ Department of internal medicine, Shahid Mostafa Khomeini Hospital, Ilam University of Medical Sciences, Ilam, Iran
}

Correspondence should be addressed to Elham Shafiei; shafiei-e@medilam.ac.ir

Received 29 July 2020; Accepted 30 October 2020; Published 12 November 2020

Academic Editor: Mehmet Armagan Osmanagaoglu

Copyright (C) 2020 Nasrin Bazgir et al. This is an open access article distributed under the Creative Commons Attribution License, which permits unrestricted use, distribution, and reproduction in any medium, provided the original work is properly cited.

\begin{abstract}
Osteoporosis is a disease known to reduce bone density and to damage bone microarchitecture leading to increased fracture risk. Osteoporosis is one of the most common diseases among the middle aged and elderly people that impose high costs on the community. So far, despite rare cases of pregnancy and lactation-associated osteoporosis (PLO) reported in Iran, it can be treated with accurate diagnosis. Patient Introduction. A 24-year-old woman was referred to the outpatient rheumatologic clinic after the cesarean section during the first pregnancy with severe back pain. In the thoracolumbar radiographs, a loss of vertebral height in the T11 to L5 vertebra was recognized. Other complaints were abdominal pain and anemia. In order to evaluate the gastrointestinal disease and celiac, the patient underwent gastrointestinal and hematologic workup. Ultimately, secondary causes of the osteoporosis were excluded. Based on the patient's clinical course, imaging finding, and exclusion of other causes of osteoporosis, the patient was diagnosed with PLO. Conclusion. Clinicians should be aware of PLO as rare complication of pregnancy. The situation should be particularly considered in females offering from new onset back pain in the third trimester of pregnancy or breastfeeding period.
\end{abstract}

\section{Introduction}

Osteoporosis is described by a decrease in bone density, and bone microarchitecture quality is lowered [1].

Osteoporosis usually develops gradually with no symptoms. It is discovered only when a fracture occurs [2].

The most common signs of osteoporosis contain fracture and pain. Frequency of pregnancy and lactation-associated osteoporosis (PLO) is valued to be 4-8 individuals for every one million women $[3,4]$.

During pregnancy or breastfeeding, the healthy females are rarely affected by the PLO. Pregnancy has no risk factors for osteoporotic fractures $[5,6]$ arising commonly at the thoracolumbar vertebral [7-9]. The PLO was identified almost in $70 \%$ of the women through their first pregnancy [10].

During pregnancy, mainly, the third trimester of the fetal bone skeleton necessities totalling $30 \mathrm{~g}$ of calcium (the equiv- alent of 250-300 mg daily calcium) should be provided from the mother [11].

Lactating women drop daily a usual amount of $210 \mathrm{mg}$ of calcium during breastfeeding. This means that after the first six months of breastfeeding, every lactating woman loses a total of calcium four times more than that of pregnancy period [12].

As far as the PLO is concerned, both the increased weight-bearing and lordotic posture in pregnant women would lead to low bone mass. Also, skeletal fragility may lead to spine fractures just because of a low trauma [13].

\section{Patient Introduction}

The patient is a 24-year-old woman complaining of severe back pain. The patient was under medical treatment, but the nonsteroidal anti-inflammatory drugs (NSAIDs) along with physiotherapy had nothing to alleviate the pain. In the 

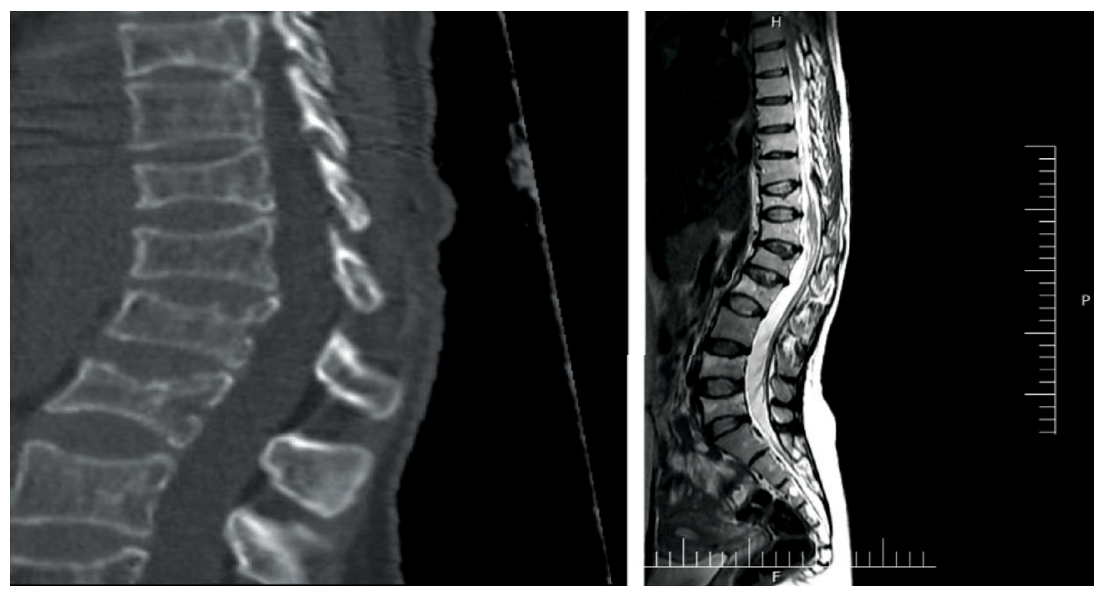

FIgURE 1: The result of a patient's imaging indicating fracture in the (T11-L5) vertebral.

TABLE 1: Laboratory markers before and 18 months after treatment.

\begin{tabular}{lccc}
\hline Index & $\begin{array}{c}\text { Before } \\
\text { treatment }\end{array}$ & $\begin{array}{c}\text { After } \\
\text { treatment }\end{array}$ & $\begin{array}{c}\text { Normal } \\
\text { range }\end{array}$ \\
\hline $\begin{array}{l}\text { 25OH vitamin D } \\
(\mathrm{ng} / \mathrm{ml})\end{array}$ & 29 & 40 & $10-30$ \\
Phosphorus (mg/dl) & 2.7 & 3.3 & $2.5-4.5$ \\
Intact PTH (pg/ml) & 18 & 12 & $10-66$ \\
$\begin{array}{l}\text { 24h urine calcium } \\
(\mathrm{mg} / \mathrm{dl})\end{array}$ & 124 & 180 & $100-250$ \\
Calcium (mg/dl) & 8.5 & 8.9 & $8.5-10.5$ \\
ALP (IU/l) & 306 & 319 & $200-350$ \\
\hline
\end{tabular}

TABLE 2: BMD before and 18 months after treatment.

\begin{tabular}{lcccc}
\hline & \multicolumn{2}{c}{$\mathrm{L}(1-4)$} & \multicolumn{2}{c}{ Femur neck } \\
& $\begin{array}{c}\text { Before } \\
\text { treatment }\end{array}$ & $\begin{array}{c}\text { After } \\
\text { treatment }\end{array}$ & $\begin{array}{c}\text { Before } \\
\text { treatment }\end{array}$ & $\begin{array}{c}\text { After } \\
\text { treatment }\end{array}$ \\
\hline T-score & -3.6 & -1.8 & -3.1 & -1.9 \\
$\begin{array}{l}\text { Z-score } \\
\mathrm{BMD}\end{array}$ & -3.3 & -1.8 & -3 & -2 \\
$\left(\mathrm{~g} / \mathrm{cm}^{2}\right)$ & 0.540 & 0.580 & 0.510 & 0.560 \\
\hline
\end{tabular}

BMD: bone mineral densitometry.

thoracolumbar radiographs, a loss of vertebral height in the T11-L5 was detected.

In the same area, multiple compression fractures were illustrated through (MRI) (Figure 1). The dual-energy Xray absorptiometry (Hologic Discovery system) was applied to quantify the bone mineral density (BMD) at the vertebral spine and the hip. The BMD confirmed the osteoporosis. In addition, the patient was suffering from abdominal pain and anemia. Gastrointestinal examinations and related tests were normal as reported by the gastroenterologist. Only anemia due to iron deficiency was reported by an oncologist for further blood tests. Other examinations were healthy.

The patient was advised to discontinue lactation as soon as PLO was established. Immediately, we prescribed calcium $500 \mathrm{mg}$ per day, vitamin D3 50000 every 2 weeks, and teri- paratide $20 \mu \mathrm{g} / \mathrm{d}$. An improvement in the patient's pain and movement was seen three weeks after the therapy (Table 1). As far as the spinal and hip BMD are concerned, the control BMD was shown to be increased 18 months after the treatment. We were faced with no novel fractures during the treatment (Table 2).

\section{Discussion and Conclusion}

Although osteoporosis happens at middle age and senile population, osteoporosis is uncommon in pregnancy.

Primiparous women are affected by the PLO. Risk factors of PLO included fractures and PLO in the first degree families, osteoporosis history, vitamin $\mathrm{D}$ deficiency, low body mass index (BMI), inadequate intake of calcium, low physical activity, therapy with anticoagulants and ppi, elevated parathyroid hormone-related protein (PTHrP) and high rates of bone turnover, and finally smoking $[14,15]$. Disabled LBP and reduced height resulted from fractures in the vertebral osteoporosis in the third trimester or in the lactation period. Termination of breastfeeding, bisphosphonates prescription, and supplementation of calcium and vitamin D are considered as the main frequently used therapies for PLO.

One of the rare causes of back pain during pregnancy is the PLO which occurs mostly when the woman is pregnant for the first time. Occasionally, back pain shows itself in the third trimester or when the woman has delivered. Another significant indicator of the PLO is height loss. As reported, both the lower thoracic and the lumbar spine are known as the two most affected sites by fractures. It is evident that the loss of the BMD in the spine is more common and severe compared to the other parts of the skeleton [16].

Increased bone turnover is quite obvious during pregnancy and lactation. Maternal bones deliver to the fetus $110-120 \mathrm{mg} / \mathrm{kg} / \mathrm{d}$ of calcium, and during the third trimester, the mother experiences a decreased BMD in the range of 2$4 \%$. Lactation period is attributed to higher calcium loss about $300 \mathrm{mg} /$ day compared to the pregnancy period. The breastfeeding women lose about 1-3\% of BMD per month. As far as bone metabolism is concerned, prolactin and the parathyroid-related peptide (PTHrP) are the main 
modulators during pregnancy and breastfeeding. Prolactin secretion is stimulated by lactation which in turn decreases the gonadotropin production, and this leads ultimately to the secretion of lower levels of estradiol. Also, the production of PTHRP is increased by prolactin and, on the other hand, increased the PTHRP along with the low estradiol making synergistically the bone resorption.

\section{Conflicts of Interest}

The authors report no conflicts of interest in this work.

\section{Acknowledgments}

We thank our colleagues from the Clinical Research Development Unit, Mostafa Khomeini Hospital, who provided insight and expertise that greatly assisted the research.

\section{References}

[1] T. A. Pontes, A. D. Barbosa, R. D. Silva, M. R. Melo-Junior, and R. O. Silva, "Osteopenia-osteoporosis discrimination in postmenopausal women by $1 \mathrm{H}$ NMR-based metabonomics," PLoS One, vol. 14, no. 5, p. e0217348, 2019.

[2] D. Kim, S. K. Kim, S. J. Lee, H. J. Choo, J. W. Park, and K. Y. Kim, "Simultaneous estimation of the fat fraction and R2* via $\mathrm{T} 2 *$-corrected 6 -echo Dixon volumetric interpolated breath-hold examination imaging for osteopenia and osteoporosis detection: correlations with sex, age, and menopause," Korean Journal of Radiology, vol. 20, no. 6, pp. 916-930, 2019.

[3] M. Gehlen, A. D. Lazarescu, C. Hinz et al., "Pregnancy and lactation-associated osteoporosis," Zeitschrift für Rheumatologie, vol. 76, no. 3, pp. 274-278, 2017.

[4] L. J. Li, J. Zhang, P. Gao et al., "Clinical characteristics and bisphosphonates treatment of rare pregnancy- and lactationassociated osteoporosis," Clinical Rheumatology, vol. 37, no. 11, pp. 3141-3150, 2018.

[5] N. Hong, J. E. Kim, S. J. Lee, S. H. Kim, and Y. Rhee, "Changes in bone mineral density and bone turnover markers during treatment with teriparatide in pregnancy- and lactationassociated osteoporosis," Clinical Endocrinology, vol. 88, no. 5, pp. 652-658, 2018.

[6] M. Kitajima and O. Chaki, "Pharmacological treatment for pregnancy and lactation associated osteoporosis," Clinical Calcium, vol. 29, no. 1, pp. 70-76, 2019.

[7] A. Sanchez, M. B. Zanchetta, and K. Danilowicz, "Two cases of pregnancy- and lactation- associated osteoporosis successfully treated with denosumab," Clinical Cases in Mineral and Bone Metabolism, vol. 13, no. 3, pp. 244-246, 2016.

[8] X. D. He, W. B. Xia, X. P. Xing et al., "Clinical features of pregnancy and lactation-associated osteoporosis: analysis of 4 cases," Zhonghua Yi Xue Za Zhi, vol. 89, no. 14, pp. 983-985, 2009.

[9] R. Terzi, H. Terzi, T. Ozer, and A. Kale, "A rare cause of postpartum low back pain: pregnancy- and lactation-associated osteoporosis," BioMed Research International, vol. 2014, Article ID 287832, 2014.

[10] K. Lampropoulou-Adamidou, G. Trovas, I. P. Stathopoulos, and N. A. Papaioannou, "Case report: teriparatide treatment in a case of severe pregnancy -and lactation- associated osteo- porosis," Hormones (Athens, Greece), vol. 11, no. 4, pp. 495500, 2012.

[11] T. Kuroda, T. Nagai, K. Ishikawa, and K. Inagaki, "Clinical features and diagnosis of lumbar fractures caused by pregnancyand lactation-associated osteoporosis," Clinical Calcium, vol. 29, no. 1, pp. 46-50, 2019.

[12] C. Pabinger, C. Heu, A. Frohner, and H. P. Dimai, "Pregnancyand lactation-associated transient osteoporosis of both hips in a 32 year old patient with osteogenesis imperfecta," Bone, vol. 51, no. 1, pp. 142-144, 2012.

[13] M. Zhang, P. Chen, B. Li, J. Du, T. Pan, and J. Chen, "Approach to the patient with pregnancy and lactationassociated osteoporosis: a case report and a review of the literature," Medicine, vol. 96, no. 46, p. e8671, 2017.

[14] A. Mangela-Gomes, M. L. Garcia-Rosa, E. Massae-Yokoo, V. Wahrlich, D. Garbin-Di Luca, and D. M. Martinez-Ceron, "Prevalence of osteopenia, osteoporosis and their risk factors in the Niterói family doctor program," Salud Pública de México, vol. 61, no. 2, pp. 100-101, 2019.

[15] N. Kadam, S. Chiplonkar, A. Khadilkar, and V. Khadilkar, "Low knowledge of osteoporosis and its risk factors in urban Indian adults from Pune city, India," Public Health Nutrition, vol. 22, no. 7, pp. 1-8, 2019.

[16] M. Raffin, O. Bonnot, M. Giannitelli et al., "Hormonal risk factors for osteoporosis: different profile among antipsychotics," Journal of Child and Adolescent Psychopharmacology, vol. 28, no. 10, pp. 719-726, 2018.

[17] F. Pouresmaeili, B. Kamali Dehghan, M. Kamarehei, and G. Yong Meng, "A comprehensive overview on osteoporosis and its risk factors," Therapeutics and Clinical Risk Management, vol. 14, pp. 2029-2049, 2018. 